\title{
Metabolic Syndrome in Schizophrenia
}

\author{
Ghimire SR', Rai Y2
}

\begin{abstract}
1. Consultant Psychiatrist and Project Manager, Transcultural Psychosocial Organization Nepal (TPO Nepal), Baluwatar, Kathmandu, Nepal 2. Lecturer, Department of Psychiatry, Nobel Medical College, Biratanagar, Nepal
\end{abstract}

E-mail *Corresponding author: $\underline{\text { drsrghimire@gmail.com }}$

\begin{abstract}
Metabolic syndrome (MS), a constellation of interconnected metabolic disorders including obesity (central and abdominal), hyperglycemia, dyslipidemias and hypertension is highly prevalent among patients with schizophrenia. The prevalence of MS varies across countries and ethnic groups. There are multiple determinants of MS among patient with schizophrenia, important being age, sex, ethnic group, longer duration of illness, advanced age, and use of antipsychotics. Early detection and management of metabolic abnormalities could prevent associated premature morbidity and mortality in schizophrenia. Future research is needed to identify and explore genetic determinants of MS in schizophrenia which could help to prevent and manage the illness in better way.
\end{abstract}

Keywords: Metabolic Syndrome, Schizophrenia, Obesity

\section{INTRODUCTION}

Psychiatric disorders are found among the leading cause of global morbidity. ${ }^{1}$ Schizophrenia is one among them which has chronic course with poor prognosis. ${ }^{2}$ Patients suffering from schizophrenia have a reduced life expectancy as compared to the general population. 3-7 Moreover, they have 2-3 fold increased risk of dying due to several reasons. ${ }^{8}$ Patients with mental illness including schizophrenia are neglected in all societies and their physical health is not given priority and attention. Because of illness itself and chronic use of antipsychotics along with co-morbid substance abuse, patients with schizophrenia are always in high risk of developing metabolic syndrome (MS).9-12 Undiagnosed and untreated co-morbidities were seen in significant proportion of patients in Clinical Antipsychotic Trials of Intervention Effectiveness (CATIE). ${ }^{9}$ There is increased mortality rate observed in schizophrenia due to cardiac cause, so growing concern has been given to the physical illness especially cardiovascular risk among these patients. ${ }^{13}$ The main reason is that these patients are more likely to be overweight, smoke excessively and develop hyperglycaemia, hypertension, and dyslipidaemia. ${ }^{14,15}$

Schizophrenia

Schizophrenia is a chronic and disabling psychiatric illness ${ }^{16}$ that has around 1\% lifetime risk and affects young age group. ${ }^{17}$ Approximately, half of patients with schizophrenia probably requiring long-term medication due to chronic nature of illness. ${ }^{18} \mathrm{It}$ has a life time prevalence of 4.0/1000 individuals worldwide. ${ }^{19}$ Onset is usually during adolescence or early adulthood affecting both male and female equally. ${ }^{20}$ The most prominent characteristic symptoms of schizophrenia are hallucinations, delusions, and disorganization, which may lead to dangerous or bizarre behaviors which are also known as positive symptoms. ${ }^{16,19}$ Similar other symptoms so-called negative symptoms such as social 
withdrawal and diminished emotional engagement, loss of motivation, poverty of speech and cognitive impairments can significantly impair social and occupational functioning. ${ }^{16,19}$ It also result in persistent negative impact on patient ability to maintain relationships and engage in productive work in addition to disorganized thinking and memory impairments..$^{20}$ There is evidence that more than $90 \%$ of patients with schizophrenia have sleep problems $^{21}$ which may exacerbate existing psychopathology by causing distress and negative impact on general functioning. ${ }^{21}$ It has serious physical, social and economic consequences, ${ }^{20}$ which is often accompanied by relapse even while on treatment. ${ }^{17}$ The chronic and deteriorating nature of course makes this illness disabling disorder for patients and their families.22-4 There is a great negative impact of illness on quality of life of patients and carers. ${ }^{25-7}$

\section{Metabolic Syndrome}

MS is characterized by a constellation of interconnected metabolic disorders including obesity (central and abdominal), hyperglycaemia, dyslipidemias and hypertension. ${ }^{28}$ It is also commonly known as insulin resistance syndrome or "X syndrome". There are number of definitions of MS along with several diagnostic criteria are used in clinical setting. Majorities of them used in these various definitions include waist circumference, low high density lipoprotein (HDL) level and raised triglycerides (TG), fasting plasma glucose (FPG) and blood pressure (BP). The widely accepted ones are those proposed by (a) National Cholesterol Education Program Adult Treatment Panel III (NCEP- ATP III), ${ }^{5}$ (b) updated ATP-III,29 revised by the American Heart Association/ National Heart, Lung, and Blood Institute, AHA/NHLBI; and International Diabetes Federation (IDF). ${ }^{7}$ World Health Organization(WHO) ${ }^{30}$ defined MS as insulin resistance and/or impaired fasting glucose and/or impaired glucose tolerance and two or more of the following: (i) waist-hip ratio $>0.90$ (men), $>0.85$ (women) or body mass index $>30 \mathrm{~kg} / \mathrm{m}^{2}$., (ii) triglyceride level $>1.7 \mathrm{mmol} / \mathrm{L}$ or high-density lipoprotein $<0.9 \mathrm{mmol} / \mathrm{L}$ (men), $<1.0 \mathrm{mmol} / \mathrm{L}$ (women), (iii) blood pressure $>140 / 90 \mathrm{~mm} \mathrm{Hg}$ (or treated hypertension), and (iv) microalbuminuria. Similarly, NCEP ATP III
5 had proposed the definition of MS which was later revised in 2005 by the American Heart Association/National Heart, Lung, and Blood Institute (updated ATP III).30 Waist circumference, blood pressure, HDL and TG are found common in these two definitions whereas FPG measurement is found to be different. Similarly, IDF proposed another definition on it. ${ }^{7}$ Diagnostic of MS depend upon the criteria used and population being studies. As Asian population have small build, the metabolic risk profile in Asian descent has been reported to be more adverse than that in European descent at the same waist circumference. ${ }^{31}$ Thus, the recommended cut-off for waist circumference in the NCEP ATP III definition is inappropriate for Asian populations. The most current definition done by IDF focused on the importance of waist circumference, using both more stringent and ethnic-/race-specific criteria. Waist circumference is smaller than ATP III and updated ATP III. Emphasis is given on abdominal obesity in this definition where (abdominal circumference of $\geq 90$ and $\geq 80 \mathrm{~cm}$ respectively for male and female of Asian origin, and of $102 \mathrm{~cm}$ and $88 \mathrm{~cm}$ respectively for nonAsians). The other criteria are triglyceride levels $\geq 150 \mathrm{mg} / \mathrm{dl}$, high density lipoproteins (HDL) $<40 \mathrm{mg} / \mathrm{dl}$ and $50 \mathrm{mg} / \mathrm{dl}$ for men and women respectively, a systolic blood pressure $\geq 130 \mathrm{~mm}$ of mercury $(\mathrm{Hg})$ or a diastolic blood pressure $\geq 85 \mathrm{~mm}$ of $\mathrm{Hg}$, and fasting plasma glucose levels $\geq 100 \mathrm{mg} / \mathrm{dl} .{ }^{7}$ The IDF and updated ATP III criteria overlap and identify essentially the same individuals as having MS. ${ }^{28}$ The major difference between these is the necessity of central obesity for making a diagnosis; while the IDF definition needs central obesity plus any other two or more out of five criteria, the updated ATP III definition requires any three or more of the five criteria for a diagnosis. Past studies revealed variation in outcome rates in same population when different criteria were used to calculate MS.9,10,32-3 These study found IDF criteria usually generated the highest rates and NCEP-ATP III modified criteria generated the lowest rates.

MS is associated with a four times relative risk of developing diabetes ${ }^{31}$ and approximately a 2fold risk of coronary heart disease, stroke, and premature mortality. ${ }^{9}$ As a result, MS has been proposed as an alternative or an augmentation 
to the Framingham ${ }^{10}$ or systematic coronary risk evaluation ${ }^{11}$ calculations to assess the risk of cardiovascular disease and death. Similar results for the MS as a predictor of the risk of coronary heart disease have been found previously in schizophrenia. 32

\section{Metabolic Syndrome among Patient with Schizophrenia}

Metabolic abnormalities have consistently been identified among patient with schizophrenia since decade. ${ }^{34}$ Schizophrenia does not just affect mental health of a person but is found to be associated with increased mortality and shortened life expectancy. ${ }^{15}$ Patients are more likely to die prematurely due to physical health problems especially metabolic abnormalities. ${ }^{35-6}$ The reason for excess mortality among patient with MS is mostly related to circulatory, respiratory, digestive, genitourinary and endocrine diseases including diabetes. ${ }^{37}$ As past studies pointed out the mortality in schizophrenia was especially due to suicide and other natural causes, however more recent study found co-morbid medical conditions along with cardio-metabolic illnesses is the leading cause. ${ }^{38}$ MS increases mortality from cardiovascular diseases from numerous causes. Schizophrenic patients are always at a greater risk of developing obesity, diabetes mellitus type 2, hypertension and dyslipidemia than other due to a number of reasons, including sedentary lifestyle, poor dietary choices, decreased physical activity, smoking, alcohol \& substance abuse and side effects of antipsychotic medications. ${ }^{39}$ It has been well established fact that metabolic abnormalities among schizophrenic patients not only have an impact on physical health but also on poorer quality of life, ${ }^{40}$ non-compliance, ${ }^{41-5}$ and lower functional outcome. ${ }^{46}$ The CATIE study found that MS are often under-recognized as well as undertreated in schizophrenia in which $88 \%$ of patients with dyslipidaemia were not receiving treatment, $62 \%$ were found to be hypertensive patients and $38 \%$ of them had diabetes. ${ }^{47}$ Thus special attention has been given to prevent mortality and morbidity related to MS in schizophrenia since last several years. ${ }^{14}$

\section{Prevalence}

The prevalence of MS in populations around the world varies in urban populations from $8 \%$ in India to $24 \%$ in USA among men and from $7 \%$ in France to $46 \%$ in Iran among women. ${ }^{48}$ A study involving around 14,425 participants in Eastern Nepal estimated that the prevalence of MS using the IDF criteria was $22.5 \%$ and $20.7 \%$ based on NCEP ATP III criteria. ${ }^{49}$ Globally prevalence of MS among patient with schizophrenia is found to be higher than general population. It is found approximately two-to three-folds higher than in the general population.9, $50-1$ The prevalence study of metabolic syndrome in schizophrenia differs from ethnic group and geographic location. Studies among Asian population reported lower rates of MS in schizophrenia and on the other hand western population showed high rates of MS. Prevalence of MS ranges from $20 \%$ in Thailand ${ }^{52}$ to $22 \%$ in Taiwan. ${ }^{53}$

Research carried out among patient with severe mental disorder in Hong Kong ${ }^{54}$ has estimated the unadjusted prevalence of MS to be $35 \%$. The study revealed the relative risk of MS in comparison with the general Hong Kong population was 2.008 (95\% CI 1.59-2.53, p $<0.0001)$. A Korean cross-sectional study 55 has estimated the prevalence of $43.4 \%$ of MS and was found approximately similar among men $(43 \%)$ and women $(43.9 \%)$. The MS prevalence among 1186 patients with schizophrenia and schizoaffective disorder in Japan based on ATPIII definition was $27.5 \%$. ${ }^{56}$ The study found out higher rate $(29.8 \%)$ in male than in female patients $(25.3 \%)$. Few studies have been carried out in South Asian countries. Studies about prevalence rates of MS in South Asians region tend to be somewhat different from East Asian countries. A study regarding MS among 227 patients with schizophrenia in India using IDF criteria found $43.6 \%$, and $44.5 \%$ using NCEP ATP III met the criteria for MS. ${ }^{57}$ Similarly, another study carried out in similar setting using the IDF criteria found out the prevalence of $37.8 \%{ }^{58}$ Studies carried out in the USA has estimated the prevalence of MS in schizophrenia to be between $28.7 \%{ }^{59}$ and $60 \% .{ }^{60}$ Research done in other western countries apart from USA and Australia revealed approximately similar study findings that of Asian countries. A Canadian study ${ }^{61}$ found out the prevalence rate of $44.7 \%$, 
and a Finnish Project ${ }^{62}$ estimated the rate of $37.1 \%$.

\section{Risk factors for Metabolic Syndrome}

Central obesity is a key feature of the MS reflecting the fact that there is strong relationship between waist circumference and increasing adiposity. ${ }^{28}$ Many components of the MS are associated with sedentary life style including increased central obesity, reduced HDL cholesterol level, high blood pressure, increased triglyceride level and increase glucose level. ${ }^{63}$ Many life style factors such as poor dietary habits, smoking, drinking may increase risk of MS. ${ }^{64}$

It is estimated that approximately $75 \%$ of patient with type-2 DM or impaired glucose tolerance (IGT) have MS. The presence of MS in this population group is found to be related to higher prevalence of cardiovascular disorder compared with those patients having type-2 DM or IGT without syndrome. ${ }^{63}$ MS is found more among those people having cardiac diseases and hypertension.63-7 Prevalence of MS demonstrated by the study in coronary heart disease is approximately $50 \%$ among which $37 \%$ is premature. ${ }^{65}$ The age dependency of MS prevalence is seen in most population throughout the world and prevalence was found to be increased in older age. $56,68-73$

\section{Socio-demographic predictors}

Many attempts have been made to study the socio-demographic predictors of MS in patients with schizophrenia; however none of the sociodemographic variable has emerged as a consistent predictor of MS. 10,55-6,74-7

\section{Metabolic syndrome and sex}

The relationship of gender and occurrence of MS in schizophrenia is mixed. Many studies compared prevalence rates between men and women, and found no gender difference between patients with schizophrenia with or without MS. ${ }^{74-7}$ Other studies reported high rate of MS prevalence among female pouulation. ${ }^{10,51,70,72,78-9}$ However, very few studies reported high prevalence of MS among male population. ${ }^{73}$

\section{Metabolic syndrome and age}

The relationship of metabolic syndrome with age is almost established fact. The prevalence of MS increases with age in the general population and a similar findings were demonstrated by several past studies 56,68-72, however, fewer studies reported no age differences. ${ }^{60} \mathrm{~A}$ contrast study finding of Kang et al. ${ }^{55}$ showed the limited relationship of older age with MS to males only. Correlation of peak MS rate with age demonstrated mixed result. MS was found to be peak in the third, fourth or fifth decade of life which subsequent decline in later life. ${ }^{56}$ This study finding was not consistent through all studies, as other study found sex variation in peak MS rates. ${ }^{56}$

\section{Metabolic syndrome and ethnicity}

Metabolic syndrome among patients with schizophrenia is common in all ethnic groups. However, limited studies have addressed the issue of ethnicity in estimating the metabolic rates. ${ }^{60,68,74}$ These studies found out black African and Hispanic patients appeared to have higher rates of MS.

\section{Metabolic Syndrome and Educational Status}

Education is seen as a good indicator for social position, socio-economic status and health status of an individual. It helps to shape the healthy behavior of a person through knowledge, attitude and healthy practice. In recent years increase prevalence of metabolic syndrome is seen among educated people due to life style changes. ${ }^{80}$ Similar trend is seen in Schizophrenia as some studies finding reported higher education level among patient with schizophrenia. ${ }^{81-2}$ However, no correlation of MS with educational status was also reported in the past study. ${ }^{57}$

\section{Metabolic syndrome and other factors}

Few studies have reported association of MS with living in urban areas, ${ }^{57}$ employed status ${ }^{75,83}$ and marital status. ${ }^{83}$

\section{MS and duration of illness}

Several studies ${ }^{10,57,70}$ correlated duration of illness with MS in patients with schizophrenia. These studies reported that longer duration of illness increased the chance of having high rate of MS. However, no association of MS and 
duration of illness were also reported by some syudies. ${ }^{84}$

\section{Drug naive patients versus medicated patients}

There is vast difference on occurrence of metabolic syndrome between patient who are under medication and who never been on medication. The prevalence rates to range from $11 \%$ to $69 \%$ in patient under antipsychotics, and $4-26 \%$ in drug naive patients. ${ }^{85}$ Initially base line prevalence in drug- naive patients vary from $0 \%$ to $14 \%$ and it increases to approximately $52.4 \%$ by 3 months of antipsychotic medication treatment. MS rate is depending upon the type of antipsychotic medication prescribed to the patient. Patients under second generation antipsychotics tend to develop higher rate of MS than patient who are taking first generation antipsychotic. ${ }^{86}$ A study among patients with schizophrenia in 2000 to 2006 compared with 1984 to 1995 explored that patient who were under second generation antipsychotic had more than twice the rate of new incident cases of MS after 3 years, compared with those treated with first generation antipsychotics $(27.8 \%$ vs 9.8\%). ${ }^{47}$ The pioneer study in schizophrenia , CATIE study showed concordance finding. ${ }^{9}$

\section{Clinical predictors}

Number determinants were found to be associated with clinical predictors of MS in schizophrenia. Conflicting results regarding age of onset, duration of the disorder, smoking and number of hospitalization have been observed.52,56 Some studies have shown no association of MS and duration of illness, ${ }^{84}$ however, other studies with a longer duration of illness has been demonstrated to be associated with higher prevalence of MS in some of the studies.10,70 Late age of onset is viewed as potential predictor of MS, 52 while contrast finding is also exist relating to such association. ${ }^{87}$ It also depend upon modality of treatment. Patient who treated as out- patient were more prone to develop MS than those who treated as in-patient. ${ }^{56}$ There are inconsistent findings regarding association of smoking and MS shown by past studies. Some studies reported higher prevalence of MS in patients who smoke, ${ }^{70,88}$ while other studies reported no differences in terms of smoking. ${ }^{10,60,71,75}$
Researchers reported higher body mass index (BMI) in patients with schizophrenia with MS.72,89 Most patients with schizophrenia diagnosed with MS have raised waist circumference, ${ }^{57,71-3}$ while the least have raised FPG level. ${ }^{57,72}$ De Hert and colleagues $^{40}$ concluded that adding FPG measurement to waist circumference was the most sensitive (100\%) method to follow MS in patients with schizophrenia. Patient with schizophrenia tend to smoke more than general population, however, smoking was found no difference between patients with or without MS $.10,68,71$

\section{Psychotropics and metabolic syndrome}

Patient with schizophrenia have to take antipsychotic medication for the longer duration which has potential risk of MS. Use of atypical antipsychotics has been cited as one of the reason for increased prevalence of MS in schizophrenia. $33,69,82,90-7$ Most common antipsychotics associated with MS are second generation antipsychotics, important being clozapine, olanzapine and risperidone. $33,69,93$ Risk of MS is lower for amisulpride, aripiprazole, sertindole, ziprasidone, haloperidol and chlorpromazine. ${ }^{33,90,92}$ Literature suggests that the prevalence of MS is approximately reaches up to $69 \%$ in medicated patients ${ }^{91}$ while it is lower in the range of $3-26 \%$ in drug naive patients. ${ }^{93}$ Another study revealed the concordance finding regarding the prevalence rates between drug naive patients and those on treatment and demonstrated that the prevalence rates was nearly double in those treatment. ${ }^{92}$ Although most of the studies found difference in weight gain property between typical and atypical antipsychotics, some studies ${ }^{96-7}$ have concluded that there is no difference in their propensity to cause MS. The increased risk to develop MS under antipsychotic drugs is in part related to drug induced weight gain. ${ }^{93}$ Although all antipsychotics can induce weight changes, the relative risk to induce clinically relevant weight changes difference approximately more than 7\% is clearly seen between antipsychotic drugs. ${ }^{94-5}$ Poly-pharmacy is associated with some degree of weight change and MS 51,67, however contrast findings are also existing with some literature..$^{76,98}$ 


\section{CONCLUSION}

MS is a major public health problem in patient with schizophrenia and multiple contributing factors determine the high prevalence of metabolic disturbances. Morbidity and mortality associated with MS in schizophrenia is preventable and special attention should be given to high risk patients. All patients undergoing antipsychotic treatment should be screened prior to starting medication and then after initiating it on regular basis. The cornerstone of early detection and management of MS is comprehensive monitoring as recommended by different available guidelines. Psychiatrist should employ multiple strategies to minimize the metabolic risk by using medication with less adverse effect of metabolic abnormalities and promoting healthy lifestyle habits. Focus on future research to identify genetic determinants of MS in schizophrenia could be cornerstone in the prevention and management.

\section{REFERENCES:}

1.Sing SM, Matto SK. Metabolic syndrome \& psychiatric disorders. Indian J Med Res. 2008;208:237-45.

2.The Global Burden of Disease. Geneva; World Health Organization.2008.

3. Reaven GM. Banting lecture 1988. Role of insulin resistance in human disease. Diabetes. 1988;37(12):1595-607.

4.Alberti KG, Zimmet PZ. Definition, diagnosis and classification of diabetes mellitus and its complications. Part 1: diagnosis and classification of diabetes mellitus provisional report of a WHO consultation. Diabetic medicine : a journal of the British Diabetic Association. 1998;15(7):539-53.

5.Expert Panel on Detection E, Treatment of High Blood Cholesterol in A. Executive Summary of The Third Report of The National Cholesterol Education Program (NCEP) Expert Panel on Detection, Evaluation, And Treatment of High Blood Cholesterol In Adults (Adult Treatment Panel III). Jama. 2001;285(19):2486-97.

6.Grundy SM, Cleeman JI, Daniels SR, Donato KA, Eckel $R H$, Franklin BA, et al. Diagnosis and management of the metabolic syndrome. American Heart Association/ National Heart, Lung, and Blood Institute Scientific Statement. Circulation. 2005;112:2735-52.

7.Alberti KG, Zimmet P, Shaw J. Metabolic syndrome--a new world-wide definition. A Consensus Statement from the International Diabetes Federation. Diabetic medicine : a journal of the British Diabetic Association. 2006;23(5):46980 .

8.Lear SA, Toma M, Birmingham CL, Frohlich JJ. Modification of the relationship between simple anthropometric indices and risk factors by ethnic background. Metabolism: clinical and experimental. 2003;52(10):1295-301.

9.McEvoy JP, Meyer JM, Goff DC, Nasrallah HA, Davis SM, Sullivan L, et al. Prevalence of the metabolic syndrome in patients with schizophrenia: baseline results from the Clinical Antipsychotic Trials of Intervention Effectiveness (CATIE) schizophrenia trial and comparison with national estimates from NHANES III. Schizophrenia research. 2005;80(1):19-32.

10. Correll CU, Frederickson AM, Kane JM, Manu P. Metabolic syndrome and the risk of coronary heart disease in 367 patients treated with secondgeneration antipsychotic drugs. The Journal of clinical psychiatry. 2006;67(4):575-83.

11. Cerit C, Ozten E, Yildiz M. [The prevalence of metabolic syndrome and related factors in patients with schizophrenia]. Turk psikiyatri dergisi = Turkish journal of psychiatry. 2008;19(2):124-32.

12. Saddichha $S$, Manjunatha $N$, Ameen $S$, Akhtar $S$. Metabolic syndrome in first episode schizophrenia - a randomized double-blind controlled, short-term prospective study. Schizophrenia research. 2008;101(1-3):266-72.

13. Homel P, Casey D, Allison DB. Changes in body mass index for individuals with and without schizophrenia, 1987-1996. Schizophrenia research. 2002;55(3):277-84.

14. Ford ES, Giles WH, Dietz WH. Prevalence of the metabolic syndrome among US adults: findings from the third National Health and Nutrition Examination Survey. Jama. 2002;287(3):356-9.

15. Saha S, Chant D, McGrath J. A systematic review of mortality in schizophrenia: is the differential mortality gap worsening over time? Archives of general psychiatry. 2007;64(10):1123-31.

16. Garzya V, Forbes IT, Gribble AD, Hadley MS, Lightfoot AP. Studies towards the identification of a new generation of atypical antipsychotic agents. Bioorg. Med. Chem. Lett. 2007; 17:400-5.

17. Kazadi NJB, Moosa MYH, Jeenah FY. Factors associated with relapse in schizophrenia. SAJP 2008; 14:52-62.

18. Lean MEJ, Pajonk FG. Patients on Atypical Antipsychotic Drugs: Another high-risk group for type 2 diabetes. DiabetesCare. 2003; 26:1597-1605.

19. Stip E, Tourjman V. Aripiprazol in Schizophrenia and Schizoaffective Disorder: A Review. ClinicalTherapeutics. 2010; 32:S3-S20.

20. Csernansky JG, Mahmoud R, Brenner R. A Comparison of Risperidone and Haloperidol for the Prevention of Relapse in Patients with Schizophrenia. N Engl JMed. 2002; 346:16-22.

21. Dursun S M, Patel J K M, Burke J G. Effects of typical antipsychotic drugs and risperidone on the quality of sleep in patients with schizophrenia: a pilot study. J Psychiatry Neurosci. 1999; 24:333-7. 
22. Jose S. A study of family burden associated with schizophrenic patients. Behavioural Scientist. 2000; 1: 59-63.

23. Loukissa D.A. Family burden in chronic illness: a review of research studies. Journal of Advanced Nursing. 1995; 21: 248-55.

24. Katschnig $H$, Krautgartner $M$, Schrank $B$, Angermeyer MC. Quality of life in depression. In: Katschnig H, Freeman H, Sartorius N (eds) Quality of life in mental disorders, 2nd edn. Wiley New York, 2005.

25. Eack SM, Newhill CE. Psychiatric symptoms and quality of life in schizophrenia: a meta-analysis. Schizophr Bull. 2007;33:1225-37

26. Chadda RK, Singh TB, Ganguly KK. Caregiver burden and coping: A prospective study of relationship between burden and coping in caregivers of patients with schizophrenia and bipolar affective disorder. Social Psychiatry Psychiatric Epidemiology. 2007; 42: 923-30.

27. Narasipuram S, Kasimahanti S. Quality of life and perception of burden among caregivers of persons with mental illness. AP J Psychol Med. 2012;13(2) : 99-103.

28. 28.Kaur J. A Comprehensive Review on Metabolic Syndrome. Cardiol Res Pract. 2014:943162.

30. Grundy SM, Cleeman JI, Daniels SR, Donato KA, Eckel RH, Franklin BA, et al. Diagnosis and management of the metabolic syndrome. American Heart Association/ National Heart, Lung, and Blood Institute Scientific Statement. Circulation. 2005;112:2735-52.

31. Alberti KG, Zimmet PZ. Definition, diagnosis and classification of diabetes mellitus and its complications. Part 1: diagnosis and classification of diabetes mellitus provisional report of a WHO consultation. Diabetic medicine : a journal of the British Diabetic Association. 1998;15(7):539-53.

32. Lear SA, Toma M, Birmingham CL, Frohlich JJ. Modification of the relationship between simple anthropometric indices and risk factors by ethnic background. Metabolism: clinical and experimental. 2003;52(10):1295-301.

33. Correll CU, Frederickson AM, Kane JM, Manu P. Metabolic syndrome and the risk of coronary heart disease in 367 patients treated with secondgeneration antipsychotic drugs. The Journal of clinical psychiatry. 2006;67(4):575-83.

34. Saddichha S, Manjunatha N, Ameen S, Akhtar S. Metabolic syndrome in first episode schizophrenia - a randomized double-blind controlled, short-term prospective study. Schizophrenia research. 2008;101(1-3):266-72.

35. Homel P, Casey D, Allison DB. Changes in body mass index for individuals with and without schizophrenia, 1987-1996. Schizophrenia research. 2002;55(3):277-84.

36. Allebeck P. Schizophrenia: a life-shortening disease. Schizophrenia bulletin. 1989;15(1):81-9.
37. Brown S. Excess mortality of schizophrenia. A metaanalysis. The British journal of psychiatry : the journal of mental science. 1997;171:502-8.

38. Brown $S$, Inskip H, Barraclough B. Causes of the excess mortality of schizophrenia. The British journal of psychiatry : the journal of mental science. 2000;177:212-7.

39. Hennekens $\mathrm{CH}$. Prevention of premature mortality among patients with schizophrenia: the need for primary prevention efforts in cardiovascular disease. CNS spectrums. 2008;13(6 Suppl 10):9-10.

40. Curkendall SM, Mo J, Glasser DB, Rose Stang $M$, Jones JK. Cardiovascular disease in patients with schizophrenia in Saskatchewan, Canada. The Journal of clinical psychiatry. 2004;65(5):715-20.

41. De Hert $M$, Peuskens B, van Winkel $R$, Kalnicka D, Hanssens L, Van Eyck D, et al. Body weight and selfesteem in patients with schizophrenia evaluated with B-WISE. Schizophrenia research. 2006;88(1-3):2226.

42. Weiden PJ, Mackell JA, McDonnell DD. Obesity as a risk factor for antipsychotic noncompliance. Schizophrenia research. 2004;66(1):51-7.

43. Acosta FJ, Hernández JL, Pereira J, Herrera J, Rodríguez CJ. Medication adherence in schizophrenia. World J Psychiatr. 2012; 2(5): 74-82.

44. Verdoux $H$, Lengronne I, Liraud F, Gonzales B, Assens F, Abalan F, van Os J. Medication adherence in psychosis: predictors and impact on outcome. A 2year follow-up of firstadmitted subjects. Acta Psychiatr Scand. 2000; 102: 203-10.

45. Velligan DI, Weiden PJ, Sajatovic M, Scott J, Carpenter D, Ross $R$, Docherty JP. The expert consensus guideline series: adherence problems in patients with serious and persistent mental illness. J Clin Psychiatry. 2009; 70, 4: 47-8.

46. Marcus T. Awareness of illness and non-compliance to antipsychotic medications among persons with schizophrenia. Psychiatr Serv. 2005; 27: 110-24.

47. Lyketsos CG, Dunn G, Kaminsky MJ, Breakey WR. Medical comorbidity in psychiatric inpatients: relation to clinical outcomes and hospital length of stay. Psychosomatics. 2002;43(1):24-30.

48. Nasrallah HA, Meyer JM, Goff DC, McEvoy JP, Davis SM, Stroup TS, et al. Low rates of treatment for hypertension, dyslipidemia and diabetes in schizophrenia: data from the CATIE schizophrenia trial sample at baseline. Schizophrenia research. 2006;86(1-3):15-22.

49. Cameron AJ, Shaw JE, Zimmet PZ. The metabolic syndrome: prevalence in worldwide populations. Endocrinology and metabolism clinics of North America. 2004;33(2):351-75.

50. Sharma SK, Ghimire A, Radhakrishnan J, Thapa L, Shrestha NR, Paudel $N$, et al. Prevalence of hypertension, obesity, diabetes, and metabolic syndrome in Nepal. International journal of hypertension. 2011;2011:821971. 
51. De Hert MA, van Winkel R, Van Eyck D, Hanssens $L$, Wampers $M$, Scheen $A$, et al. Prevalence of the metabolic syndrome in patients with schizophrenia treated with antipsychotic medication. Schizophrenia research. 2006;83(1):87-93.

52. Cohn T, Prud'homme D, Streiner D, Kameh $H$, Remington G. Characterizing coronary heart disease risk in chronic schizophrenia: high prevalence of the metabolic syndrome. Canadian journal of psychiatry Revue canadienne de psychiatrie. 2004;49(11):75360.

53. Srisurapanont $M$, Likhitsathian $S$, Boonyanaruthee $V$, Charnsilp C, Jarusuraisin N. Metabolic syndrome in Thai schizophrenic patients: a naturalistic oneyear follow-up study. BMC psychiatry. 2007;7:14.

54. Littrell KH, Petty R, Ortega TR, Moore D, Ballard $A$, Clough R, Lan TS, Selby C. Insulin resistance and Syndrome $X$ among patients with schizophrenia. Abstract Presented at: The American Psychiatric Association Annual Meeting; 2003 May; San Francisco.

55. Bressington DT, Mui J, Cheung EF, Petch J, Clark $A B$, Gray $R$. The prevalence of metabolic syndrome amongst patients with severe mental illness in the community in Hong Kong--a cross sectional study. BMC psychiatry. 2013;13:87.

56. Kang SH, Kim KH, Kang GY, Lee KH, Kim KK, Soh $M$, et al. Cross-sectional prevalence of metabolic syndrome in Korean patients with schizophrenia. Schizophrenia research. 2011;128(1-3):179-81.

57. Sugawara N, Yasui-Furukori N, Sato Y, Umeda T, Kishida I, Yamashita H, et al. Prevalence of metabolic syndrome among patients with schizophrenia in Japan. Schizophrenia research. 2010;123(2-3):244-50.

58. Grover S, Aggarwal M, Dutt A, Chakrabarti S, Avasthi A, Kulhara $P$, et al. Prevalence of metabolic syndrome in patients with schizophrenia in India. Psychiatry research. 2012;200(2-3):1035-7.

59. Mattoo SK, Singh SM. Prevalence of metabolic syndrome in psychiatric inpatients in a tertiary care centre in north India. The Indian journal of medical research. 2010;131:46-52.

60. Straker DA, Rubens E, Kosby F, Kramer E, Manu P. The prevalence of the metabolic syndrome among patients treated with atypical antipsychotic. Abstract Presented at: The American Psychiatric Association Annual Meeting; 2003; San Francisco.

61. Kato MM, Currier MB, Gomez CM, Hall L, Gonzalez-Blanco M. Prevalence of Metabolic Syndrome in Hispanic and Non-Hispanic Patients With Schizophrenia. Primary care companion to the Journal of clinical psychiatry. 2004;6(2):74-7.

62. John AP, Koloth $R$, Dragovic M, Lim SC. Prevalence of metabolic syndrome among Australians with severe mental illness. The Medical journal of Australia. 2009;190(4):176-9.

63. Heiskanen $T$, Niskanen L, Lyytikainen $R$, Saarinen PI, Hintikka J. Metabolic syndrome in patients with schizophrenia. The Journal of clinical psychiatry. 2003;64(5):575-9.

64. Hosseini Z, Whiting SJ, Vatanparast H. Current evidence on the association of the metabolic syndrome and dietary patterns in a global perspective. Nutr Res Rev. 2016 ;29(2):152-62.

65. Eckel RH, Grundy SM, Zimmet PZ. The Metabolic Syndrome. Lancet. 2005;356:1415-28.

66. Tune JD, Goodwill AG, Sassoon DJ, Mather KJ. Cardiovascular consequences of metabolic syndrome. Transl Res. 2017 May;183:57-70.

67. Ricci G, Pirillo I, Tomassoni D, Sirignano A, Grappasonni I. Metabolic syndrome, hypertension, and nervous system injury: Epidemiological correlates. Clin Exp Hypertens. 2017;39(1):8-16.

68. Liu X, Luo X, Liu $Y$, Sun X, Han C, Zhang L, Wang $B$, Ren $Y$, Zhao $Y$, Zhang $D, H u$, Zhang $M$. Resting heart rate and risk of metabolic syndrome in adults: a dose-response meta-analysis of observational studies. Acta Diabetol. 2017 Mar;54(3):223-35.

69. Lamberti JS, Olson D, Crilly JF, Olivares T, Williams GC, Tu X, et al. Prevalence of the metabolic syndrome among patients receiving clozapine. The American journal of psychiatry. 2006;163(7):1273-6.

70. Mitchell AJ, Vancampfort D, Sweers $K$, van Winkel $R$, Yu W, De Hert M. Prevalence of metabolic syndrome and metabolic abnormalities in schizophrenia and related disorders--a systematic review and meta-analysis. Schizophrenia bulletin. 2013;39(2):306-18.

71. 60. Sweileh WM, Zyoud SH, Dalal SA, Ibwini S, Sawalha AF, Ali I. Prevalence of metabolic syndrome among patients with schizophrenia in Palestine. BMC psychiatry. 2012;12:235.

72. Yazici MK, Anil Yagcioglu AE, Ertugrul A, Eni N, Karahan $S$, Karaagaoglu E, et al. The prevalence and clinical correlates of metabolic syndrome in patients with schizophrenia: findings from a cohort in Turkey. European archives of psychiatry and clinical neuroscience. 2011;261(1):69-78.

73. Huang MC, Lu ML, Tsai CJ, Chen PY, Chiu CC, Jian DL, et al. Prevalence of metabolic syndrome among patients with schizophrenia or schizoaffective disorder in Taiwan. Acta psychiatrica Scandinavica. 2009;120(4):274-80.

74. Kraemer S, Minarzyk A, Forst T, Kopf D, Hundemer HP. Prevalence of metabolic syndrome in patients with schizophrenia, and metabolic changes after 3 months of treatment with antipsychotics--results from a German observational study. BMC psychiatry. 2011;11:173.

75. Basu R, Brar JS, Chengappa KN, John V, Parepally $H$, Gershon S, et al. The prevalence of the metabolic syndrome in patients with schizoaffective disorder-bipolar subtype. Bipolar disorders. 2004;6(4):314-8.

76. Gulzar M, Rafiq A, OCuill M. Prevalence of metabolic syndrome in elderly schizophrenic patients in Ireland.Eur Arch Psychiatry Clin Neurosci. 2009;259(l 1):S85. 
77. Falissard B, Mauri M, Shaw K, Wetterling T, Doble A, Giudicelli $A$, et al. The METEOR study: frequency of metabolic disorders in patients with schizophrenia. Focus on first and second generation and level of risk of antipsychotic drugs. International clinical psychopharmacology. 2011;26(6):291-302.

78. WHO. The Asia Pacific Perspective: Redefining Obesity and its Treatment. World Health Organization, Western Pacific Region. WHO/IASO/IOTF; 2000.

79. Cerit C, Vural M, Bos Gelmez SU, Ozten E, Aker AT, Yildiz M. Metabolic syndrome with different antipsychotics: a multicentre cross-sectional study. Psychopharmacology bulletin. 2010;43(4):22-36.

80. Boke O, Aker S, Sarisoy G, Saricicek EB, Sahin AR. Prevalence of metabolic syndrome among inpatients with schizophrenia. International journal of psychiatry in medicine. 2008;38(1):103-12.

81. Kang SH, Lee JI, Chang AK, Joo YH, Kim CY, Kim SY. Genetic Polymorphisms in the HTR2C and Peroxisome Proliferator-Activated Receptors Are Not Associated with Metabolic Syndrome in Patients with Schizophrenia Taking Clozapine. Psychiatry investigation. 2011;8(3):262-8.

82. Grover S, Nebhinani N, Chakrabarti S, Avasthi A, Kulhara $P$. Metabolic syndrome among patients receiving clozapine: A preliminary estimate. Indian journal of pharmacology. 2011;43(5):591-5.

83. Pallava A, Chadda RK, Sood M, Lakshmy $R$. Metabolic syndrome in schizophrenia: a comparative study of antipsychotic-free/naive and antipsychotictreated patients from India. Nordic journal of psychiatry. 2012;66(3):215-21.

84. Grover $S$, Nebhinani N, Chakrabarti S, Avasthi A, Kulhara $P$, Basu D, et al. Comparative study of prevalence of metabolic syndrome in bipolar disorder and schizophrenia from North India. Nordic journal of psychiatry. 2014;68(1):72-7.

85. Yoon BH, Bae A, Bahk WM. Prevalence and characteristics of metabolic syndrome in schizophrenic inpatients. Schizophr Res. 2008;102:244.

86. Malhotra N, Grover S, Chakrabarti S, Kulhara P. Metabolic syndrome in schizophrenia. Indian journal of psychological medicine. 2013;35(3):227-40.

87. Luft B, Taylor D: A review of atypical antipsychotic drugs versus conventional medication in schizophrenia. Expert Opin Pharmacother 2006, 7:1739-48.

88. Kaya MC, Virit O, Altindag A, Selek $S$, Bülbül F, Bulut $M$, et al. Prevalence of metabolic syndrome, characteristics of metabolic syndrome and relationship with the antipsychotics used in schizophrenia.Nöropsikiyatri Arşivi. 2009;46:13.

89. Ellingrod VL, Miller DD, Taylor SF, Moline J, Holman T, Kerr J. Metabolic syndrome and insulin resistance in schizophrenia patients receiving antipsychotics genotyped for the methylenetetrahydrofolate reductase (MTH-FR)
$677 \mathrm{C} / \mathrm{T}$ and $1298 \mathrm{~A} / \mathrm{C}$ variants. Schizophr Res. 2008;98:47-54

90. Hagg $S$, Lindblom Y, Mjorndal T, Adolfsson R. High prevalence of the metabolic syndrome among a Swedish cohort of patients with schizophrenia. International clinical psychopharmacology. 2006;21(2):93-8.

91. Meyer JM, Stahl SM. The metabolic syndrome and schizophrenia. Acta psychiatrica Scandinavica. 2009;119(1):4-14.

92. Tirupati S, Chua LE. Obesity and metabolic syndrome in a psychiatric rehabilitation service. The Australian and New Zealand journal of psychiatry. 2007;41(7):606-10.

93. Gautam S, Meena PS. Drug-emergent metabolic syndrome in patients with schizophrenia receiving atypical (second-generation) antipsychotics. Indian journal of psychiatry. 2011;53(2):128-33.

94. Sahoo S, Ameen S, Akhtar S. Metabolic syndrome in drug-naive first-episode psychosis treated with atypical antipsychotics. The Australian and New Zealand journal of psychiatry. 2007;41(7):629.

95. Newcomer JW. Second-generation (atypical) antipsychotics and metabolic effects: a comprehensive literature review. CNS drugs. 2005;19(1):91-3.

96. Haddad PM, Sharma SG. Adverse effects of atypical antipsychotics : differential risk and clinical implications. CNS drugs. 2007;21(11):911-36.

97. Correll CU, Frederickson AM, Kane JM, Manu P. Does antipsychotic polypharmacy increase the risk for metabolic syndrome? Schizophrenia research. 2007;89(1-3):91-100.

98. De Hert $M$, Mauri M, Shaw K, Wetterling T, Doble A, Giudicelli A, et al. The METEOR study of diabetes and other metabolic disorders in patients with schizophrenia treated with antipsychotic drugs. I. Methodology. International journal of methods in psychiatric research. 2010;19(4):195-210.

99. Krane-Gartiser K, Breum L, Glumrr C, Linneberg A, Madsen $M$, Koster $A$, et al. Prevalence of the metabolic syndrome in Danish psychiatric outpatients treated with antipsychotics. Nordic journal of psychiatry. 2011;65(5):345-52. 